Original article (short paper)

\title{
Comparison of electromyographic activity during the bench press and barbell pullover exercises
}

\author{
Yuri de Almeida Costa Campos \\ Sandro Fernandes da Silva \\ Federal University of Lavras, Brazil
}

\begin{abstract}
The aim of the study was to compare the electromyographic (EMG) activity of the following muscles: clavicular portion of pectoralis major, sternal portion of pectoralis major, long portion of triceps brachii, anterior deltoid, posterior deltoid and latissimus dorsi during dynamic contractions between flat horizontal bench press and barbell pullover exercises. The sample comprised 12 males individuals experienced in resistance training. The volunteers made three visits to the laboratory. The first one consisted of 12 repetitions of the exercises for the electromyographic data collection. The results showed a higher EMG activation of the pectoralis major and anterior deltoid muscles in the flat horizontal bench press in comparison with the barbell pullover. The triceps brachii and latissimus dorsi muscles were more activated in the barbell pullover.
\end{abstract}

Keywords: EMG, exercises, upper-body, horizontal bench press, barbell pullover

Resumo - "Comparação da atividade eletromiográfica entre os exercícios supino horizontal e pull-over na barra." O objetivo do estudo foi comparar a atividade eletromiográfica dos músculos peitoral maior porção clavicular, peitoral maior porção externa, porção longa do tríceps braquial, deltóide anterior, deltóide posterior e grande dorsal durante contrações dinâmicas entre os exercícios supino horizontal e pull-over. A amostra foi composta por 12 indivíduos do sexo masculino experientes em treinamento resistido. Os voluntários fizeram três visitas ao laboratório; a primeira consistiu na avaliação antropométrica e no teste de $1 \mathrm{RM}$ em ambos os exercícios, e a segunda e terceira consistiram na realização de 12 repetições para a coleta dos dados da eletromiografia. Após a análise dos resultados foi possível identificar uma ativação eletromiográfica superior dos músculos peitoral maior e deltóide anterior no supino horizontal em relação ao pull-over barra. Já as musculaturas do tríceps braquial e grande dorsal foram mais ativadas no pull-over barra.

Palavras-chave: EMG, exercício, parte superior do tronco, supino, pull-over

Resumen-“Comparación de la actividad electromiografíca entre los ejercicios press de banca horizontal y pull-over barra." El objetivo del estudio fue comparar la actividad electromiografíca de los músculos pectoral mayor en la porción clavicular, pectoral mayor porción esternal, porción larga del tríceps braquial, deltoides anterior, deltoides posterior y dorsal ancho durante las contracciones dinámicas entre los ejercicios press de banca y pullover. Hicieron parte de la muestra 12 individuos del sexo masculino expertos en el entrenamiento con pesas. Los voluntarios hicieran tres visitas al laboratorio, la primera, consistió en la evaluación antropométrica y en el teste de 1RM en los dos ejercicios, y la segunda y tercera, consistió en la realización de 12 repeticiones para la recolecta de los datos de la electromiografía. Después del análisis de los resultados fue posible identificar una activación electromiografíca superior en las porciones del musculo pectoral mayor y en el deltoides anterior en el press de banca horizontal en relación al pull-over barra. Ya las musculaturas del tríceps braquial y del dorsal ancho fueron las más activadas en el pull-over barra.

Palabras clave: EMG, ejercicio, tren superior del tronco, press de banca, pull-over

\section{Introduction}

The deltoid and pectoralis major muscles are the main muscles of the glenohumeral joint, with an important function in daily activities and in numerous sports skills (Santana, Vera-Garcia, $\&$ McGill, 2007). Thus, it is important to include exercises to increase the strength of the front and upper body, either for aesthetic or therapeutic purposes. Also, such exercises can improve sport performance in which the use of a sport equipment is common, or upper body movements are required (Escamilla
\& Andrews, 2009; Schick et al., 2010). In order to achieve improved muscle performance, coaches often use the horizontal bench press exercise (Sadri et al., 2011; Schick et al., 2010; Tillaar \& Ettema 2010), especially because of its effectiveness in developing pectoral, triceps and anterior deltoid muscles (Kellis $\&$ Baltzopoulos, 1998). However, other exercises and variations of the horizontal bench press have been used to diversify training. These changes usually include modifications in the angle of the equipment seat (Barnett, Kippers, \& Turner, 1995; Glass, \& Armstrong, 1997; Trebs, Brandenburg, \& Pitney, 2010), as 
well as the use of other exercise equipments (McCaw \& Friday, 1994; Trebs, Brandenburg, \& Pitney, 2010), dumbbell exercises (Uribe et al., 2010), dumbbell fly exercises (Welsch, Bird, \& Mayhew, 2005), cables and pulleys (Clemons \& Aron, 1997; Sadri et al., 2011), and stable and unstable surfaces (Goodman et al., 2008). These are exercise alternatives routinely prescribed as a way to complement training.

Recently, a study performed by Marchetti et al. (2011) demonstrated that the barbell pullover could also be used to develop anterior and upper body muscles, the pectoralis major. However, some other reports have shown that the exercise in question also recruits latissimus dorsi fibers, without significant differences between that musculatures and muscles portions of the pectoralis major (Takara et al., 2005). When we analyzed the biomechanics of the barbell pullover exercise compared with other basic exercises used to improve the upper and front part of the body, we observed a great difference between the movements (Hall, 1999). However, even with these biomechanical differences, barbell pullover exercise is still prescribed more often to develop the musculatures of the upper and anterior parts of the trunk, besides the back part of the trunk. Such choices generate doubts about its true prescription, as they may result in different responses, especially in the levels of electrical activation on the target muscles. In order to clarify these questions, electromyography emerges as a reliable research tool, being constantly employed for the analysis of physiological aspects of muscle activity during exercise (De Luca et al, 2006; Escamilla \& Andrews, 2009).

Thus, the purpose of the study was to compare clavicular portion of pectoralis major (CPPM), pectoralis major sternal portion (PMSP), long portion of the triceps (LPTB), anterior deltoide (AD), posterior deltoide (PD) and latissimus dorsi (LD) muscles between horizontal bench press and barbell pullover exercises with trained men.

\section{Methods}

\section{Experimental approach to the problem}

In order to investigate differences in EMG activation of muscles for the horizontal bench press and the barbell pullover exercises, two test sessions were established, in which participants were assigned to perform two exercises in a random order in different sessions. The EMG signal was recorded during the concentric and eccentric phases of each of 12 repetitions in order to compare the levels of muscle activation in CPPM, PMSP, LPTB, DA, DP and LD. Participants were selected according to their experience in resistance training and in the target exercises.

\section{Participants}

Participants for this study consisted of 12 men (age: 24.50 \pm 4.34 years, relative body fat: $13.63 \pm 1.94 \%$, height: 176.0 $\pm 0.04 \mathrm{~cm}$, body mass: $73.12 \pm 6.10 \mathrm{~kg}$ and, years of training: $3.58 \pm 2.90$ ). To be included in the study, they could not have bone nor muscle disorders that could compromise the execution of movements. Also, they should have minimum experience of 12 months in resistance training, and be familiar with the horizontal bench press and the barbell pullover exercises. Participants were instructed to refrain from any form of physical activity for a period of 48 hours prior the tests. All volunteers signed an Informed Consent Form, previously approved by the Committee of Ethics and Research Involving Human Subjects of the Central University of South of Minas (UNIS), Minas Gerais State, Brazil (protocol 0068/2010). Volunteers made three visits to the laboratory. The first consisted in the clarification of the likely questions regarding the research, the signing of the Informed Consent Form, anthropometric assessments, 1RM test, and explanation about the required movements speed during the exercises. For the measurement of the sample characteristics, data of height and weight were collected using a scale with Welmy ${ }^{\circledR}$ stadiometer. The estimated body fat percentage was measured through a Quantum BIA-II ${ }^{\circledR}$ tetra polar bioimpedance apparatus (RJL Systems, Inc. Clinton: US-MI). Conmed ${ }^{\circledR}$ electrodes were used for the data collection. The 1RM test followed the protocol NSCA (Earle \& Baechle, 2004), in which participants progressively increased resistance until 1RM was found. The movement speed was monitored via a digital metronome, and pre-establishing 2 seconds for the concentric phase, and 2 seconds for the eccentric one, totaling 4 seconds for a movement or 1 repetition. In the second and third visits, participants performed the exercises presented in a random order. Before testing, participants underwent the EMG preparation protocol to avoid skin impedance, and then performed a series of 20 repetitions as a specific warm up, with a load set at $30 \%$ of their respective body mass. Then, a new set of 12 repetitions at $70 \% 1 \mathrm{RM}$ was performed to record the EMG signal. To perform BP we used a bar measuring $1.20 \mathrm{~m}$ long, mass $6 \mathrm{~kg}$, a HBP and Physicus ${ }^{\circledR}$ washers (Brazil). In the initial execution of the movement, participants lay down on a bench in a supine position, feet flat on the ground, holding a barbell with a pronated grip, and upper limb perpendicular to the body. Grip distance was determined by the bi-acromial width of each participant. The movement ended when the barbell was elevated above the participants' head, and then, moving down just below an imaginary line of the bench. For the horizontal bench press, we used a bar measuring $1.30 \mathrm{~m}$ long, mass of 10 $\mathrm{kg}$, a horizontal bench press and Physicus ${ }^{\circledR}$ washers (Brazil). Hands were positioned on the barbell, which was individually adjusted with a variation from 10 to $30 \mathrm{~cm}$ out of the shoulder joint (Wagner et al., 1992). In the initial position of the movement, individuals lay down on the bench in a supine position, with their feet flat on the ground, holding the barbell with a pronated grip to start the exercise. At the start of the eccentric phase of the movement, participants were instructed to direct the barbell in a line near the central region of the sternum. The end of the eccentric phase and the beginning concentric one occurred when the barbell was moved near $2 \mathrm{~cm}$ of the chest. Participants were instructed not to touch the chest with the barbell in order to prevent the electrodes to move or to detach while performing the exercise. 


\section{Electromyography}

To avoid potential interference with the EMG signal, each participant's skin area was prepared before placing the electrodes through the processes of trichotomy, abrasion and cleaning with isopropyl alcohol. Two electromyography Miotool 400 (Miotec Biomedical Equipment Ltd., POA, Brazil ${ }^{\circledR}$ ) with 4 input channels, 14 bit resolution and an acquisition rate of 2,000 per channel samples, with a sensor SDS-500 with a maximum gain of 1000 times were used for the data collection with Common Mode Rejection in $110 \mathrm{~dB}$. The electrodes used were $3 \mathrm{M}^{\circledR}$ model $2223 \mathrm{BR}$, with a catchment surface with $\mathrm{Ag} / \mathrm{AgCl} 1 \mathrm{~cm}$ diameter in the shape of discs. The electrodes were attached to the individual's body according to the points proposed by Merletti et al. (1999), respecting a distance of $2 \mathrm{~cm}$, and parallel to the muscle fibers. The low impedance of the skin was evaluated $(<2 \mathrm{k} \Omega)$ and each channel of the electromyography was properly calibrated before the data collection. After attaching the electrodes in the muscles portions to be analyzed, the biding sites were marked with demographic pencil to avoid any interference between evaluators and the different days on which the tests were applied. All measurements were taken on the right side of the individual's body. Reference electrodes were placed on the clavicle and the styloid process of the ulna. Electromyography data were collected and stored in a personal computer (Samsung RV411, Samsung, Brazil).

\section{Signal processing}

Signals collected were filtered through $5^{\text {th }}$ order Butterworth band-pass type filter with a $20-500 \mathrm{~Hz}$ cutoff frequency. The amplitude of the signals was expressed by the square root of the average values. To avoid any possibility of phase delay during the signal filtering, an extended time of EMG signal was determined with an interval of 1 minute. For analysis and data processing Miograph 9 Build 2.0 Alpha 5 software was used.

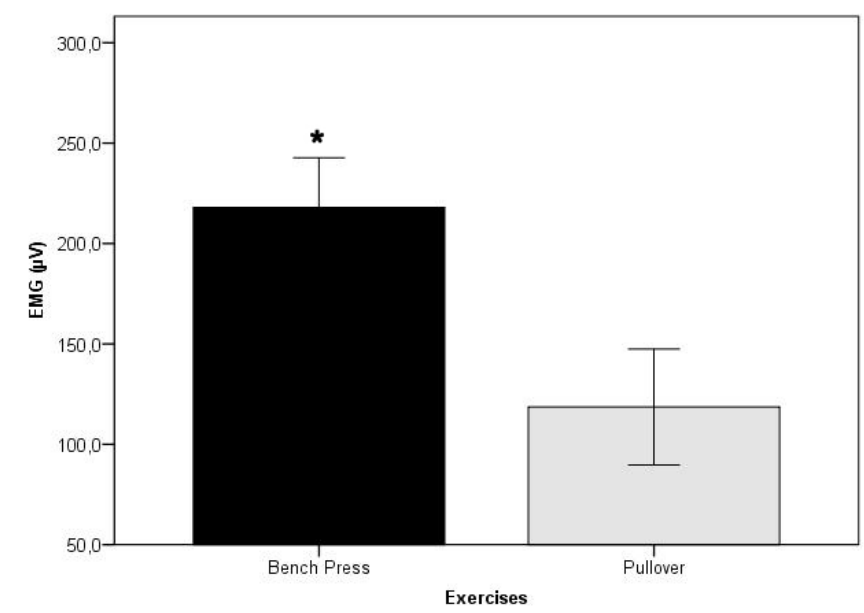

Figure 1. Comparison of electromyographic activation of the major pectoral clavicular portion between horizontal bench press and barbell pullover exercises (mean and SD). ${ }^{\#} p<0.05$ - significant difference

\section{Data organization process for statistical analysis}

From the raw signal (RAW) it was possible to make a cut in the original signal of 12 repetitions ( 48 seconds) in a new signal of 8 repetitions ( 36 seconds), i.e., we excluded the first two and the last two repetitions. We adopted these criteria in order to prevent the sample from failing to exert the proper speed of execution during the initial and final moments of the exercise, thus minimizing the chances of error. Soon after, the new signal was handled from the $5^{\text {th }}$ order band-pass type Butterworth filter with a cutoff frequency of 20-500 Hz. The electromyographic signal amplitude was calculated in RMS (Root Mean Square). The signals were normalized according to the maximum peak of the EMG signal. Then, mean signals of all participants were obtained and transferred into the SPSS software version 20.0 (SPSS, Inc., Chicago, IL, USA) for statistical analysis.

\section{Statistical analysis}

Data analysis was performed with statistical comparison of averages and standard deviations. In order to investigate the distribution of the sample, Shapiro-Wilk test was used. Statistical analysis of the activation of muscle groups between the horizontal bench press and barbell pullover exercises adopted the $t$-test for independent samples. To identify the performance between muscle activations within each exercise, $t$-test for dependent samples was adopted. In order to verify the effect size of the sample test, $d$ Cohen was adopted. For statistical evidence $\alpha<0.05$ was adopted.

\section{Results}

The ICC between repetitions was 0.99 (lower limit $=-0.003$, upper limit $=0.281$ ). Figure 1 shows the comparison of electromyography activity of the major pectoral clavicular portion between the horizontal bench press and barbell pullover exercises ( $p<0.01, d=0.628$, moderate effect size). The results

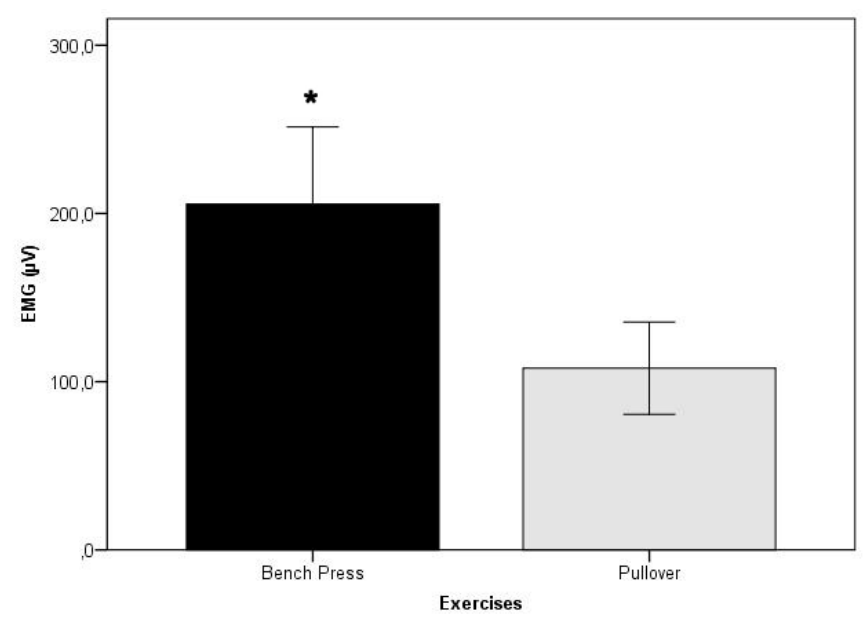

Figure 2. Comparison of the electromyographic activation of major pectoral sternal portion between horizontal bench press and barbell pullover exercises (mean and SD). ${ }^{\#} p<0.05$ - significant difference \# $p<0.05$ - significant difference between BP and HBP 


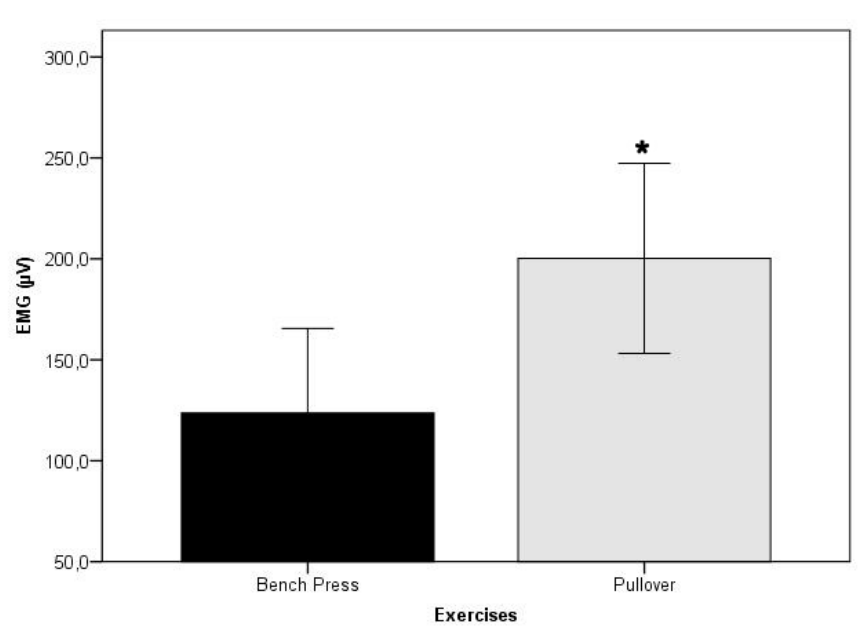

Figure 3. Comparison of electromyographic activation of brachial triceps long portion between horizontal bench press and barbell pullover exercises (mean and SD).

indicated significant differences between the horizontal bench press and barbell pullover.

In Figure 2, we observed a significant difference between the studied exercises regarding electromyography in major pectoral sternal portion $(p<0.01, d=0.453$, moderate effect size). In the analysis of Figure 3, it was identified that the barbell pullover shows a statistically significant higher electromyographic activity than the horizontal bench press for the long portion of the triceps ( $p<0.014, d=0.268$, small effect size).

When checking the results of the anterior deltoid (Figure 4), we observed a higher electromyographic activity during the horizontal bench press compared to the barbell pullover $(p<$ $0.01, d=0.802$, large effect size). Figure 5 shows the result of posterior deltoid, in which we found no significant difference between both exercises $(p<0.812)$.

Figure 6 shows the latissimus dorsi muscle's electromyography, in which we found a significant difference between barbell pullover and horizontal bench press $(p<0.012, d=$ 0.303 , small effect size).

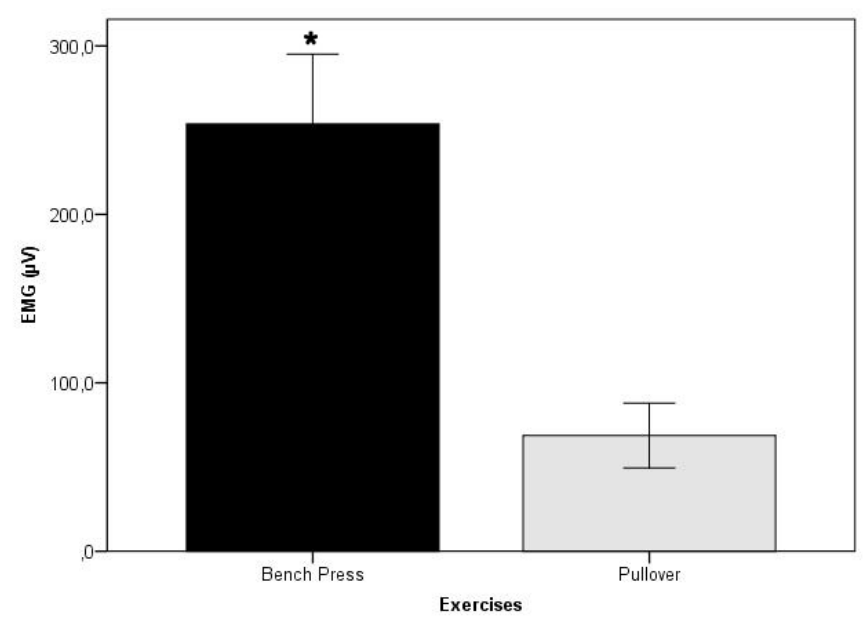

Figure 4. Comparison of electromyographic activation of anterior deltoid between horizontal bench press and Barbell Pullover exercises (Mean and SD). ${ }^{*} p<0.05$ - significant difference.

\section{Discussion}

Based on the analysis of the results it was possible to confirm the initial research hypothesis. The anterior and upper body muscles activity showed significant differences in the CPPM, PMSP, LPTB and AD muscles. During horizontal bench press, CPPM, PMSP and AD muscles showed higher levels of EMG activity in comparison with the barbell pullover. These results show that horizontal bench press presents concentric and eccentric phases only in the front and the upper part of the body, while the barbell pullover has the end of its eccentric phase and the beginning of its concentric one located in the posterior and upper body part-during which the pectoralis major musculature are most requested, being responsible for performing the flexion of the glenohumeral joint (Smith, Weiss, \& Lehmuhl, 1997; Wirhed, 1986). Another major factor that may have influenced a divergent electromyographic response between the two exercises relates to the shoulder joint's movement biomechanics. While in the horizontal bench press shoulder shows horizontal adduction and abduction (Hall, 1999; Marchetti \& Uchida, 2011) movements, in the barbell pullover the shoulder shows flexion and extension (Graham, 2004; Marchetti \& Uchida, 2011) movements.

During the barbell pullover, LPTB showed higher levels of EMG activation in comparison with the horizontal bench press (Figure 3). This higher activity of LPTB during barbell pullover was mainly attributed to the isometric action of this muscle, emphasized by a slight elbow flexion during the movement. This elbow flexion occurred in the movements of all the evaluated individuals, and apparently was due to the great distance between the axis (shoulder) and the resistance (represented by the apparatus - barbell + weight), which increased significantly the isometric request of this muscle during exercise execution. On the other hand, the horizontal bench press showed lower levels of electrical activation mainly due to the grips separation relative to the bi-acromial distance (Clemons \& Aron, 1997; Lehman, 2005). The standard grip used during the horizontal bench press basic execution did not allow the absolute recruitment of these muscles during the final concentric phase in which the extension of the elbows occurred.

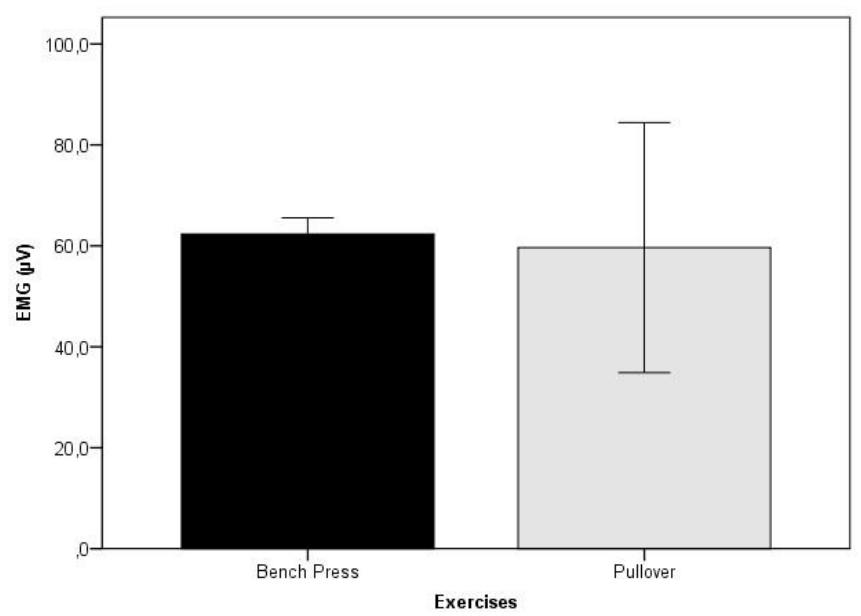

Figure 5. Comparison of electromyographic activation of posterior deltoid between horizontal bench press and barbell pullover exercises (mean and SD). 


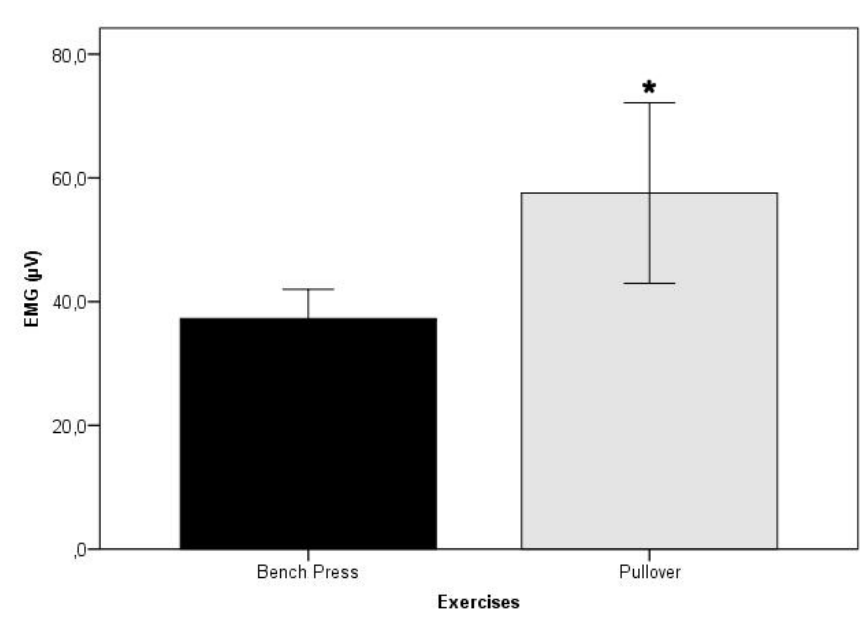

Figure 6. Comparison of electromyographic activation of latissimus dorsi between horizontal bench press and barbell pullover exercises (mean and SD). ${ }^{*} p<.05$ - significant difference

With regard the posterior and upper body muscles, the results showed a significant difference in the LD muscles, but they did not show differences in the PD muscles (Figure 5). During the barbell pullover, LD muscles showed higher levels of electrical activation regarding the horizontal bench press (Figure 6). This LD tendency of showing higher electromyographic activity during the horizontal bench press can be explained by the movement characteristic itself, which begins concentric phase and ends eccentric phase at the posterior part of the trunk.

In summary, from the results of this study, the horizontal bench press still appears as an essential exercise for the development musculature of the anterior and upper chest, given the higher levels of electrical activation regarding the barbell pullover. Thus, when the primary goal is the development of the anterior and upper body muscles, the horizontal bench press exercise and its variations still stands out as having the greatest magnitude in comparison with the barbell pullover. We recognize that this study has limitations as we did not use other variations of bench press with different bench angles, dumbells, machines and other exercises in order to compare with the barbell pullover. However, other studies (Cachio et al., 2008; Sadri et al., 2011; Schick et al., 2010; Trebs, Brandenburg, \& Pitney, 2010; Welsch, Bird, \& Mayhew, 2005) comparing the horizontal bench press with other bench press variations fail to find significant differences on levels of electrical activation on the studied muscles. Such evidence allows one to classify these variations or exercises as complementary, or (most of them) primordial and effective for the anterior and upper body development.

Therefore, according to our findings we cannot classify the barbell pullover as a complementary exercise, nor primary for the development of the anterior and upper body muscles. This is due primarily to three factors: the EMG activation levels in the evaluated muscles, and, specifically, in the portions of the pectoralis major, which are practically duplicated when comparing the horizontal bench press with the barbell pullover; the movement of the shoulder joint, (while in the barbell pullover we have flexion and extension movements, in all other variations and exercises that have been studied, we have the horizontal abduction and abduction movements) (Marchetti \& Uchida, 2011); and the electromyographic activity found in our study in the LD muscle, which shows a tendency of barbell pullover to show electrical activity in the muscle in question (Takara et al., 2005).

In conclusion, the results of this study suggest that the barbell pullover exercise cannot be indicated as an exercise for the front and upper body muscles, and that the horizontal bench press exercise is the most indicated to the training and development of this body musculature region. It is appropriate to emphasize that a variety of training programs that include specific exercises have been applied to athletes in sports where equipment is controlled and/or directed with a muscle complex of the front and the upper body parts (Escamilla \& Andrews, 2009; Schick et al, 2010). Training protocols show great applicability of these exercises in the treatment of pathologies located in the shoulders (Dorrestijn et al, 2009; Kuhn et al, 2009). Taking into account the specific movement of the barbell pullover exercise, as well as the similarity of this exercise with the varieties of movements performed during some sports modalities that require flexion and extension of the shoulder joints, injuries or pathologies in these musculatures can be prevented.

Barbell pullover is indicated as a good transition exercise from the anterior to the posterior portions of the body. With regard the adjustment of the barbell pullover in training programs, we suggest its application in agonist/antagonist training to provide take advantage of the transitional potential offered by this exercise. In sports, the barbell pullover could be usually prescribed as part of strength training for athletes in many sports modalities, both for performance improvement, enhancement of strength and power, and for the prevention of injuries (Dorrestijn et al., 2009; Kuhn et al., 2009) that may result from repetitive movements above the shoulder line (Schafle, Requa, \& Patton, 1990; Watkins \& Green, 1992). In such situations, glenohumeral joint is often requested due to the exercise specificity degree that is very similar to movements of serving and cutting in volleyball, serving in tennis and pitching in baseball, to name a few examples.

\section{References}

Barnett, C., Kippers, V., \& Turner, P. (1995). Effects of variations of the Horizontal Bench Press exercise on the EMG activity of Five shoulder muscles. Journal of Strength and Conditioning Research, 9(4): 222-227.

Cachio, A., Don, R., Ranavolo, A., Guerra, E., McCaw, S., Procaccianti, R., ... \& Santilli V. (2008). Effects of 8-weeks strength training with two models chest machines on muscular activity pattern and strength. Journal of Electromyography and Kinesiology, 18, 618-627.

Clemons, J., \& Aron, C. (1997). Effect of grip width on the myoelectric activity of the prime movers in the Horizontal Bench Press. Journal of Strength and Conditioning Research, 11, 82-87.

De Luca, C., Adam, A., Wotiz, R., Gilmore, D., \& Nawab, S. (2006). Decomposition of surface EMG signals. Journal of Neurophysiology, 96, 1646-1657.

Dorrestijn, O., Stevens, M., Winters, J.C., van der Meer, K., \& Diercks, R. L. (2009). Conservative or surgical treatment for subacromial impingement syndrome? A systematic review. Journal of Shoulder and Elbow Surgery, 18, 652-660.

Escamilla, F., \& Andrews, J. (2009). Shoulder Muscle Recruitment Patterns and Related Biomechanics during Upper Extremity Sports. Sports Medicine, 39, 569-590. 
Earle, R., \& Baechle, T. (2004). NSCA's Essentials of Personal Training. Champaign, IL: Human Kinetics.

Glass, S., \& Armstrong, T. (1997). Electromyographical activity of the pectoralis muscle during incline and decline Horizontal Bench Presses. Journal of Strength and Conditioning Research, 11, 163-216.

Goodman, C., Pearce J., Nicholes, J., \& Gatt, B. (2008). No difference in 1RM strength and muscle activation during the barbell chest press on stable and unstable surface. Journal of Strength and Conditioning Research, 22, 88-94.

Graham, J. (2004). Dumbbell Barbell Pullover. Strength and Conditioning Journal, 26, 48-49.

Hall, S. (1999). Basic Biomechanics. New York: McGraw- Hill Companies.

Kellis, E., \& Baltzopoulos, V. (1998). Muscle activation differences between eccentric and concentric isokinetic exercise. Medicine Science Sports Exercise, 30, 16-23.

Kuhn, J. E. (2009). Exercise in the treatment of rotator cuff impingement: a systematic review and a synthesized evidence based rehabilitation protocol. Journal of Shoulder and Elbow Surgery, $18,138-160$

Lehman, G. (2005). The influence of grip width and forearm pronation/supination on upper-body myoelectric activity during the flat Horizontal Bench Press. Journal of Strength and Conditioning Research, 19, 587-591.

Marchetti, P., \& Uchida, M. (2011). Effects of the Barbell Pullover exercise on the pectoralis major and latissimus dorsi muscles as evaluated by EMG. Journal of Applied Biomechanics, 27, 380-384.

McCaw, S., \& Friday, J. (1994). A comparison of muscle activity between a free weight and machine Horizontal Bench Press. Journal of Strength and Conditioning Research, 8, 259-264.

Merletti, R. (1999). Standards for Reporting EMG Data. Journal Electromyography Kinesiology, 9, 3-4.

Santana, J., Vera-Garcia, F., \& McGill, S. (2007). A Kinetic and electromyographic comparison of the standing cable press and Horizontal Bench Press. Journal of Strength and Conditioning Research, 21, 1271-1279.

Sadri, I., Jourkesh, M., Ostojic, S., Calleja-Gonzales J., Ojagi, \& Neshati A. (2011). A comparison of EMG fluctuation of deltoid and pectoralis major muscles in Horizontal Bench Press. Sports Science, 1, 30-33.

Schafle, M., Requa, R., \& Patton, W. (1990). Injuries in the 1987 national amateur volleyball tournament. American Journal of Sports Medicine, 18, 624-631.

Schick, E., Coburn, J., Lee, B., Judelson, D., Khamoui, A., Tran, T., \& Uribe, B. (2010). A comparison of muscle activation between a smith machine and free weight Horizontal Bench Press. Journal of strength and condition Research, 24, 779-784.

Smith, L. K., Weiss, E. L., \& Lehmuhl, L. D. (1997). Cinesiologia Clínica de Brunnstom. São Paulo: Manole.

Tillaar, R. \& Ettema G. (2010). The "sticking period" in a maximum Horizontal Bench Press. Journal of Sports Sciences. 28: 529-535.

Trebs, A., Brandenburg, J., \& Pitney, W. (2010). An electromyography analysis of 3 muscles surronding the shoulder joint during the performance of a chest press exercise at several angles. Journal of Strength and Conditioning Research. 24: 1925-1930.
Uribe B., Coburn W., Brown E., Judelson A., Khamoui V., \& Guyen N. (2010). Muscle activation when performing the chest press and shoulder press on a stable Horizontal Bench Press vs. swiss ball. Journal of Strength and Conditioning Research, 24, 1028-1930.

Wagner, L., Evans, S., Weir, J., Housh T., \& Johnson, G. (1992). The effect of grip width on Horizontal Bench Press performance. Journal Sport Biomechanics, 8,1-10.

Watkins, J., \& Green, B. (1992). Volleyball injuries: a survey of injuries of Scottish National League male players. British Journal of Sports Medicine, 26, 135-137.

Welsch, E., Bird, M., \& Mayhew, L. (2005). Electromyographic activity of the pectoralis major and anterior deltoid muscles during three upper-body lifts. Journal of Strength and Conditioning Research, $19,449-452$.

Wirhed, R. (1986). Atlas de anatomia do Movimento. São Paulo: Manole.

\section{Authors' note}

Yuri de Almeida Costa Campos and Sandro Fernandes da Silva are affiliated with the Group of Research and Studies on Neuromuscular Behavior (GEPREN), Department of Physical Education, Federal University of Lavras, MG, Brazil.

\section{Corresponding author}

Yuri de Almeida Costa Campos

Universidade Federal de Lavras, Departamento de Educação Física PO box 3037

Lavras 37200-000, MG, Brazil

Phone: (35) 3829-5132

email: sandrofs@def.ufla.br

\section{Acknowledgments}

Financial Support by FAPEMIG (Fundação de Amparo à Pesquisa de Minas Gerais); Junior research scholarship.

Manuscript received on July 23, 2013

Manuscript accepted on April 1, 2014

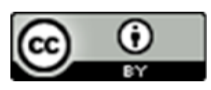

Motriz. The Journal of Physical Education. UNESP. Rio Claro, SP, Brazil - eISSN: 1980-6574 - under a license Creative Commons - Version 3.0 